\title{
Mínimo social e igualdade: deficiência, perícia e benefício assistencial na LOAS
}

\author{
Janaína Lima Penalva da Silva \\ Universidade de Brasília (UnB)
}

\author{
Debora Diniz \\ Universidade de Brasília (UnB)
}

\section{Mínimo social e igualdade: deficiência, perícia e benefício assistencial na LOAS}

Resumo: Este artigo desenvolve a ideia de que a Lei Orgânica da Assistência Social (LOAS) institui o mínimo social e fixa a sobrevivência como padrão para a prestação de assistência social. Essas definições da LOAS são inconstitucionais, porque a Constituição Federal define que a assistência social será prestada a quem dela necessitar. Para defender essa tese, o artigo se organiza em duas partes. Na primeira, é analisado o conceito de deficiência que a Convenção Internacional sobre os Direitos das Pessoas com Deficiência incorporou à Constituição Federal e seu impacto na LOAS quanto à concessão do benefício de prestação assistencial aos deficientes. Na segunda parte, é discutido o papel dos peritos para a avaliação do acesso à assistência social, conforme o entendimento imposto pelos mínimos sociais.

Palavras-chave: Direitos. Pessoas com deficiência. LOAS. BPC. Mínimo social.

\section{Social Minimum and Equality: Deficiency and LOAS Assistance Benefits}

Abstract: This article develops the idea that the Organic Law for Social Assistance (LOAS) institutes the social minimum and establishes a survival level as the standard for providing social assistance. The definitions established by LOAS are unconstitutional, because the Brazilian Constitution determines that social assistance will be provided to whoever needs it. To defend this thesis, the article is organized in two parts. The first analyzes the concept of deficiency that the International Convention about the Rights of People with Disabilities incorporated to the Federal Constitution, and its impact on the LOAS in the determination of benefits to be provided to the disabled, according to the understanding imposed by the social minimums.

Keywords: Rights. People with disabilities. LOAS. BPC. Social minimum. 


\section{Introdução}

O Decreto n. 6.949, de 25 de agosto de 2009 (BRASIL, 2009a), promulgou a Convenção Internacional sobre os Direitos das Pessoas com Deficiência - a primeira convenção da Organização das Nações Unidas do século 21. Essa Convenção provocou uma grande alteração no sistema normativo brasileiro ao instituir uma definição constitucional para a deficiência. Não havia clareza no sistema jurídico sobre quais deficiências estariam amparadas pelas proteções constitucionais e legais até a aprovação da Convenção, que, nos termos do parágrafo 3 do artigo 5 da Constituição Federal, ingressou no sistema jurídico como Emenda Constitucional ${ }^{1}$. Com a aprovação da Convenção, o cenário passou a ser outro. Pessoas com deficiência são aquelas que

[...] têm impedimentos de longo prazo de natureza física, mental, intelectual ou sensorial, os quais, em interação com diversas barreiras, podem obstruir sua participação plena e efetiva na sociedade em igualdades de condições com as demais pessoas (BRASIL, 2009a).

A nova definição de deficiência terá grandes impactos no Brasil, tanto nas questões de reconhecimento quanto nas questões de redistribuição ${ }^{2}$. Nesse último aspecto, a assistência social prestada aos deficientes no Brasil é política pública que depende diretamente da definição sobre quem são as pessoas com deficiência ${ }^{3}$. O artigo 203, inciso V, da Constituição Federal garantiu um salário mínimo de benefício mensal à pessoa com deficiência e ao idoso que comprovem não possuir meios de prover a própria manutenção ou de tê-la provida por sua família, nos termos da lei (BRASIL, 1988). O que também consta no artigo 20 da LOAS, Lei n. 8.742, de 7 de dezembro de 1993, com a redação aprimorada pela Lei n. 12.435 (BRASIL, 1993, 2011b). O Benefício de Prestação Continuada (BPC) é o principal meio de transferência de renda para a população com deficiência (BRASIL, 2007). Embora no contexto constitucional da Seguridade Social, o BPC seja parte da assistência social, sua administração e operacionalização foram delegadas ao Instituto Nacional do Seguro Social (INSS), entidade que tem como principal finalidade administrar os direitos previdenciários e não os assistenciais.

Nos procedimentos de concessão do BPC, além da prova da pobreza, os idosos atestam sua condição pelo registro civil; já os deficientes dependem da prova da deficiência, confirmada pela perícia de médicos e assistentes sociais. A perícia médica não é um procedimento diagnóstico absoluto, mas dependente do conceito de impedimentos de longo prazo, sejam eles físicos, intelectuais ou sensoriais. Até a Convenção, o conceito de deficiência era definido pela lei e regulamentado por decreto. A LOAS, em sua redação original, definia que a pessoa com deficiência era aquela incapacitada para a vida independente e para o trabalho (BRASIL, 1993). O revogado Decreto $\mathrm{n}$. 1.744 , de 8 de dezembro de 1995, que regulamentava a LOAS, estabelecia no inciso II do artigo 2 que a pessoa com deficiência era aquela incapacitada para a vida independente e para o trabalho em razão de anomalias ou lesões irreversíveis, de natureza hereditária, congênita ou adquirida, que impedissem o desempenho das atividades da vida diária e do trabalho (BRASIL, 1995). Esse conceito infralegal de deficiência - estatuído por decreto, ou seja, de forma menos democrática e mais instável - foi alterado em 1999, em 2004 e, por fim, em 2007 (BRASIL, 2007). Essas alterações percorreram um caminho de superação do paradigma biomédico e de progressiva adoção de um marco social na definição de o que constitui a experiência da deficiência. Conforme estabelecido no preâmbulo da Convenção, deficiência é um conceito em mutação (BRASIL, 2009a).

As alterações infralegais no conceito de deficiência não podem ser analisadas de forma dissociada do principal marco legal da assistência social - a LOAS -, tampouco dos alicerces distributivos que essa legislação estabelece no Brasil. Ao instituir o conceito de deficiência sob a égide da Constituição Federal, a Convenção rompeu com um passado de decretos regulamentadores que a definiam. No que toca à concessão do BPC, é preciso adequar não só o marco legal, mas também o regime pericial médico e social de avaliação da deficiência aos princípios da Convenção. A nova regulamentação para concessão do BPC disposta na LOAS incorpora o conjunto mais amplo de princípios de proteção à deficiência constantes da Convenção, mas devolve a autoridade discursiva sobre o corpo deficiente para o campo biomédico (BRASIL, 2011a). Essa adequação de regras pode ser insuficiente, tanto em termos de reconhecimento quanto de redistribuição, se não considerarmos os princípios que a fundamentam. Embora a redação atual da LOAS seja fruto de várias alterações legislativas, o caput do artigo primeiro não foi modificado. Desde sua aprovação, em 1993, essa lei estabelece que a assistência social provê os mínimos sociais, através de um conjunto integrado de ações de iniciativa pública e da sociedade, para garantir o atendimento às necessidades básicas.

A redução das necessidades aos mínimos sociais - dois conceitos que estão presentes na LOAS e que não deveriam ser tomados como sinônimos - configura uma ameaça à universalidade da assistência social no Brasil (PEREIRA, 2006). A definição de impedimentos de longo prazo que compõe o conceito de deficiência, assim como outras definições presentes na LOAS, como a de pobreza, está marcada pela 
redução das necessidades aos mínimos sociais, entendidos como a garantia de sobrevivência ou de condições mínimas de vida ${ }^{4}$. Esse é o principal argumento a ser explorado neste artigo, que toma a regulação da assistência social para os deficientes no Brasil como estudo de caso.

Este texto pretende desenvolver uma análise teórica sobre a inconformidade da LOAS aos princípios constitucionais, em especial, o princípio da igualdade. Apresentará a ideia de que a LOAS institui o mínimo social, fixando a sobrevivência como padrão para a prestação de assistência social em oposição à Constituição Federal, que define que a assistência social será prestada a quem dela necessitar. A instituição do padrão mínimo viola o princípio da universalidade, pois reduz o espectro dos sujeitos amparados pela assistência social e a medida dessa proteção. Na primeira parte, serão analisadas as alterações da LOAS de 2011 no que tange à concessão do BPC em face dos princípios instituídos pela Convenção. Em seguida, será discutido o papel dos peritos médicos para a avaliação do acesso à assistência social, conforme o entendimento padronizado imposto pelos mínimos sociais. O objetivo é demonstrar como os procedimentos, criados pela LOAS, para identificação do beneficiário, provocam uma alteração no papel da perícia que ultrapassa sua função documental, tornando os peritos médicos os julgadores.

\section{A Convenção Internacional sobre os Direi- tos das Pessoas com Deficiência e o BPC}

A Constituição Federal de 1988 garante assistência social ao deficiente e ao idoso que comprovem não possuir meios de prover a própria manutenção ou tê-la provida por sua família. Em outras palavras, determina o dever de comprovação da ausência de meios de manutenção própria ou pela família. Para a Convenção, deficiência é o resultado da interação entre os impedimentos corporais (sejam eles físicos, intelectuais ou sensoriais) e as barreiras sociais que impedem a participação. É importante esclarecer alguns conceitos que a Convenção traz para o sistema normativo brasileiro e cujos sentidos políticos a nova redação da LOAS ignora: deficiência, impedimentos, barreiras e participação.

Deficiência não se resume aos impedimentos corporais. É possível uma pessoa ter impedimentos e não experimentar restrições significativas de participação pelas barreiras existentes à vida social. Há dois pressupostos importantes nessa definição - os corpos com impedimentos não são ficções estéticas, e as barreiras compõem a organização dos ambientes. Um homem adulto cadeirante por causa de uma lesão medular vive com impedimentos físicos, mas a depender de sua renda pode ou não ter restrições significativas de participação. Um indicador objetivo de sua inclusão seria sua participação no mundo do trabalho e sua dependência do transporte para a mobilidade, por exemplo. Da mesma forma, é possível imaginar uma mulher com a mesma lesão medular e uma renda semelhante experimentando maiores restrições de participação, pela condição feminina.

O difícil, portanto, é definir quais impedimentos são significativos para qualificar um corpo como deficiente para a proteção social e quais barreiras em interação com esse corpo geram restrições de participação. A deficiência cruza-se com outras expressões da desigualdade pelo corpo, tais como, cor, gênero, sexualidade ou idade. Não é preciso ampliar esse exercício hermenêutico sobre a dificuldade de descrever corpos e classificar discriminações injustas provocadas pela ideologia da normalidade, muito embora seja isso o que a Convenção pede como compromisso dos Estados signatários. O cadeirante rico pode não experimentar diretamente restrições de participação que o qualifiquem como deficiente pobre, dependente da família e sem trabalho, para ter acesso à proteção social, mas isso não significa que não sofra discriminação.

O sentido aberto e indefinido da ideia de impedimentos é de grande valia na aplicação de direitos, na medida em que permite que o caso concreto complete o entendimento conforme uma definição justa para cada caso individual. Entretanto, a nova redação da LOAS estabelece o que significam os impedimentos. O artigo 20 da LOAS, na redação instituída pela Lei n. 12.435 e pela Lei n. 12.470, ambas de 2011, define que pessoa com deficiência é aquela com impedimentos de longo prazo que possam obstruir sua participação plena e efetiva na sociedade em igualdade de condições com as demais pessoas (BRASIL, 2011b, 2001c). Em seguida, os impedimentos de longo prazo são definidos como aqueles que produzam efeito pelo prazo mínimo de dois anos.

Esse é o texto do $\S 2$. e do $\S 10$. do artigo 20 da LOAS, que atualiza a Lei com a linguagem contemporânea da Convenção. A redação atual exclui a exigência de ausência de capacidade para a vida independente e para o trabalho, que existia na redação original do dispositivo, mas inverte o sentido da mudança ao qualificar o impedimento de longo prazo com a exigência de produção de efeitos por dois anos. Uma hipótese possível para o conceito de impedimentos oferecido pela LOAS poderia ser que a Convenção adota uma definição genérica de deficiência, cujo alvo são medidas de justiça por reconhecimento e não medidas distributivas para a igualdade. Outra hipótese seria que a Convenção não teria o poder de estabelecer ou vincular a política assistencial.

Essa separação entre medidas igualitaristas por reconhecimento e medidas distributivas não é corre- 
ta, considerando-se os princípios da Convenção. Um esvaziamento da força normativa da Convenção seria entendê-la como uma vitória no campo das lutas por reconhecimento, ignorando a vinculação que impõe em termos de distribuição. No artigo 28 da Convenção, intitulado "Padrão de Vida e Proteção Social Adequados", proteção social se vê atrelada a padrão "adequado de vida". Segundo a Convenção, a proteção social tem por objetivo garantir padrões adequados de vida, isto é, melhorar as condições de vida dos deficientes, com ênfase na garantia da igualdade, mas com especial atenção às mulheres, às crianças e aos idosos com deficiência, grupos também elencados pela Constituição Federal nos objetivos da assistência social. Se, por um lado, afirma-se o caráter universal da proteção social a todas as pessoas deficientes, por outro, enfatiza-se a particularidade desses três grupos populacionais.

Há, no entanto, novidades nessa associação da proteção social a um padrão adequado de vida, sendo a principal delas o caráter substantivo de "adequado" para a definição de qual proteção social será justa para as pessoas com deficiência. Adequado é um estado que se recusa à determinação por limites mínimos da sobrevivência, como se convencionou para o recorte de renda, por exemplo. Padrão adequado de vida não é o mesmo que simplesmente manutenção da pessoa com deficiência em sobrevida: é garantir educação, mobilidade, alimentação, trabalho, proteção, inclusão. A obrigação de garantir um padrão de vida adequado é um pressuposto de justiça que assume um compartilhamento igualitário dos bens e serviços inclusive com aqueles cidadãos "incapazes de prover a própria manutenção ou tê-la provida pela família". E medida de igualdade ter as necessidades como parâmetro e não como um padrão fixo de sobrevivência.

O artigo de proteção social da Convenção não especifica que impedimentos de longo prazo serão elegíveis à proteção social. O texto da Convenção ou melhor, o conceito de deficiência da Constituição Federal - não reduz direitos fundamentais à duração de impedimentos corporais; ao contrário, mantém a proteção social no campo das necessidades a serem protegidas para a garantia do padrão adequado de vida. Por isso, a aproximação permanente entre deficiência, pobreza e discriminação no texto da Convenção: são domínios da vida interconectados, em que a proteção de um deles não prescinde do enfrentamento dos outros.

Mesmo antes de a Convenção ser promulgada, a Constituição Federal definiu a assistência social como um direito que protege necessidades, independentemente da contribuição à Seguridade Social e, no campo da deficiência, independentemente das qualidades dos impedimentos corporais vividos por cada indivíduo.
O artigo 203 da Constituição Federal é vigoroso: estabelece que "a assistência social será prestada a quem dela necessitar" e lista seus objetivos, entre eles o já referido inciso V (BRASIL, 1988). Ao mesmo tempo em que determina que a assistência social será para quem dela necessitar, em um claro reconhecimento da necessidade como critério legítimo para a proteção social, atrela a assistência social à comprovação de renda individual e familiar, isto é, à pobreza do indivíduo e de sua família. Apesar dessa flagrante incoerência, um ponto é indiscutível: a Constituição Federal não determina que tipos de impedimentos serão elegíveis à assistência social. Um deficiente que não tenha como prover sua manutenção é elegível à proteção social.

A LOAS, na redação em vigor, copia o conceito de deficiência da Convenção ( $\$ 2$ do artigo 20), mas prejudica seu sentido e potencialidade ao definir os impedimentos de longo prazo como aqueles que produzem efeitos pelo prazo mínimo de dois anos ( $\$ 2$ e $\S 10$ do artigo 20). A Lei permanece desconsiderando o marco social da deficiência incluído no sistema constitucional brasileiro pelos princípios da Convenção. No seu artigo 12 estabelece que os Estados Partes reconheçam que as pessoas com deficiência gozam de capacidade legal em igualdade de condições com as demais pessoas em todos os aspectos da vida. A definição de regra fixa sobre o sentido de impedimento de longo prazo reduz indevidamente o âmbito protetivo da norma.

\section{Os peritos como julgadores}

A LOAS, no artigo 20, § 6, diz: “A concessão do benefício ficará sujeita à avaliação da deficiência e do grau de impedimento de que trata o $§ 2$, composta por avaliação médica e avaliação social realizadas por médicos peritos e por assistentes sociais do Instituto Nacional de Seguro Social - INSS" (BRASIL, 1993). No nível dos procedimentos, a perícia médica e social interpõe-se como critério de garantia para um direito social previsto na Constituição Federal a fim de proteger necessidades, determinando quais impedimentos caracterizar-se-ão como necessidades. Em outras palavras, é a perícia que determina quais impedimentos são de longo prazo.

A perícia médica fixa que demandas são justas e merecidas de serem protegidas pelo Estado como necessidades, ignorando o caráter universalista da abertura do já citado artigo 203 da Constituição Federal e seu inciso V. Na regulamentação desse dispositivo constitucional, a prova sobre os limites da manutenção individual e familiar transformou-se em regra bastante restritiva que, nos termos do paradigma dos mínimos, definiu o patamar de $1 / 4$ de salário mínimo per capita como recorte de pobreza para a con- 
cessão do BPC. Não há critérios objetivos que justifiquem por que esse foi o patamar de renda determinado pela LOAS, assim como não há harmonia com outros programas de transferência de renda do Governo Federal que adotam critérios diferentes de renda para inclusão nos benefícios. O Supremo Tribunal Federal já julgou esse patamar de renda constitucional, mas é possível que reveja seu posicionamento no Recurso Extraordinário 567.985/MT com repercussão geral reconhecida, ainda pendente de julgamento (PENALVA; DINIZ; MEDEIROS, 2010). De toda sorte, não houve alterações legislativas nesse ponto na reforma da LOAS de 2011.

Uma interpretação constitucionalmente adequada do direito à assistência social para a garantia da igualdade não deve abdicar de seu dever de determinar quais demandas são justas para serem protegidas pelo Estado como necessidades. O rito pericial de avaliação dos corpos, no entanto, preencheu esse espaço ambíguo deixado pela LOAS (ao mesmo tempo em que é uma política universalista, possui objetivos centrados em grupos populacionais, o que se interpreta, em nossa posição, equivocadamente, como focalização da política). São os peritos médicos do INSS quem estabelece quais impedimentos são estados de necessidade para a proteção social. A definição de um corpo com impedimentos como o de uma pessoa com deficiência não é um exercício neutro de classificação dos corpos, mas um julgamento moral que combina ideais de normalidade e produtividade. A perícia é um exercício de soberania médica no campo dos direitos sociais ${ }^{5}$.

A saída para essa medicalização da assistência não é eliminar o laudo médico-pericial. Um indivíduo sem impedimentos, porém extremamente pobre, pode requerer o BPC em nome da abertura universalista do artigo constitucional ("quem dela necessitar"), mas para se enquadrar no objetivo de proteção à pessoa deficiente ele deve comprovar a autodeclaração de que há impedimentos em seu corpo. Em outras palavras, é feita uma decisão sobre a correção do pedido de concessão do benefício assistencial. A afirmação da condição de deficiente - de que o indivíduo possui impedimentos restritivos que reduzem sua posição de igualdade social - indispensável ao requerimento de concessão do BPC deve ser verificada. Isso não significa, no entanto, que deficiência seja apenas o que a narrativa biomédica classifica sobre o corpo com impedimentos. É necessário avaliar a restrição de participação do corpo com impedimentos na vida social, por isso a urgência de a perícia social realizada por assistentes sociais ter o mesmo espaço de legitimidade que a perícia biomédica.

Nos requerimentos para a concessão do BPC, o laudo médico-pericial deveria ser, portanto, um atestado que simplesmente confirmasse ou refutasse a autodeclaração de que o indivíduo possui impedimen- tos que, em interação com as barreiras, restringiriam sua participação. Dado que a Constituição Federal prevê que a incapacidade de automanutenção individual e familiar seja comprovada, a política deveria instituir dispositivos para inscrever em termos médicos a experiência dos impedimentos corporais do indivíduo, além de estabelecer outros critérios para a mensuração da incapacidade de automanutenção. Vale notar que as possibilidades de automanutenção individual ou familiar configuram-se como um critério diferente da regra de extrema pobreza proposta pela LOAS.

Os regimes de verdade instituídos pela LOAS e executados pelo INSS foram criativos em restringir o escopo desses conceitos: a capacidade de automanutenção ou manutenção pela família passou a ser entendida como extrema pobreza (1/4 de salário mínimo) e, com a reforma de 2011, os impedimentos de longo prazo passaram a ser entendidos como aqueles que produzem efeitos pelo prazo mínimo de dois anos ( $\$ 10$ do artigo 20 da LOAS). Os impedimentos de longo prazo não foram definidos pela Convenção. Os princípios protetivos da deficiência instituídos pela Convenção, em especial a proteção à igualdade, são suficientes para entender o sentido de quais impedimentos importam para a assistência. Em alguma medida, os impedimentos de longo prazo fixam que a deficiência depende de uma restrição de participação e de interação com algum grau de durabilidade. A ideia de impedimentos de longo prazo está na Convenção como forma de garantir a proteção dos deficientes em oposição a situações muito transitórias e específicas que não demandem a construção de uma política ampla e de uma legislação própria, como os casos de doenças que não impactam na interação com o ambiente. Quando a Convenção fixa que o deficiente é aquele que possui impedimentos de longo prazo, o objetivo é delimitar as fronteiras entre diferentes estados corporais e, assim, contribuir para o reconhecimento.

No nível infralegal, o INSS, em conjunto com o Ministério do Desenvolvimento Social e Combate à Fome, editou a Portaria Conjunta MDS/INSS n. 1, em 24 de maio de 2011, antes mesmo da incorporação da Convenção ao texto da LOAS. Essa Portaria estabeleceu os critérios, procedimentos e instrumentos para a avaliação social e a médico-pericial da deficiência e do grau de incapacidade das pessoas com deficiência requerentes do BPC da Assistência Social (BRASIL, 2011a). Essa é uma norma importante de ser analisada porque é a partir de suas diretrizes que os peritos atuam. A Portaria dispõem seu artigo 3 que

O Perito Médico do INSS identificará e justificará tecnicamente, em resposta ao quesito do instrumento de avaliação, a existência de alteração im- 
portante na estrutura do corpo que implique mau prognóstico, a ser considerado no qualificador final da deficiência.

Nesse mesmo caminho, o parágrafo 2 do artigo 4 da referida norma é claro ao definir que

[...] o benefício será indeferido sempre que os impedimentos incapacitantes forem classificados como de curto ou médio prazo, independentemente do grau de incapacidade existente no momento da avaliação, reconhecido nas conclusões técnicas das avaliações social e médico-pericial.

Novamente, a reprodução do conceito de deficiência da Convenção não veio acompanhada de uma incorporação sistemática de seus princípios. Impedimentos são condições corporais que podem ter natureza física, mental, intelectual ou sensorial. Quando a interação com as diversas barreiras obstruir a participação plena e igualitária, haverá deficiência. A conceituação de "impedimentos incapacitantes" parece derivar da LOAS, quando estabelece que os impedimentos de longo prazo são aqueles que incapacitam a pessoa com deficiência para a vida independente e para o trabalho pelo prazo mínimo de dois anos (artigo 20, § 2, II da LOAS).

Dessa forma, o foco da análise da necessidade de assistência social dos deficientes dirige-se à ideia de impedimentos (ou incapacidades) de longo prazo. A Resolução é explícita em definir que o pedido será indeferido caso o impedimento não seja de longo prazo, "independen-

temente do grau de incapacidade existente no momento da avaliação, reconhecido nas conclusões técnicas das avaliações social e médico-pericial'. Essa orientação normativa se reflete nos instrumentos de avaliação social e médico-pericial da deficiência e do grau de incapacidade. Um dos quesitos do instrumento de avaliação da deficiência em vigor pelo INSS pergunta se "a deficiência implica impedimento de longo prazo? (igual ou superior a dois anos)", sendo seguido de um alerta que informa ao perito que a resposta "não" resulta em "indeferimento do pedido, independente da avaliação social e médico-pericial". Acrescido a esse item, está o quesito que avalia o "mau prognóstico" das "alterações das estruturas do corpo". Prognóstico ruim e duração dos impedimentos são as novas formas de avaliar participação, discriminação e exclusão, conceitos-chave para a Convenção, mas ignorados pelo regime pericial do INSS. Exceto pelos impedimentos graves e debilitantes, uma série de impedimentos poderá ser interpretada sob suspeita por esse novo regime de classificação dos corpos, pois se espera do perito médico algo que os saberes biomédicos se recusam a fazer, por reconhecimento da falibilidade prognóstica: cálculo de probabilidades sobre os estados corporais.

Essa redescrição da deficiência em termos estritamente trágicos (mau prognóstico e longa duração do estado de impedimento) para a entrada na proteção social tem uma razão clara: redução do impacto orçamentário do BPC para a política de assistência social, pela imposição do mínimo social. A centralidade nas ideias de duração do impedimento e prognóstico ruim viola o propósito mais fundamental da Convenção, que é assegurar a igualdade entre deficientes e não deficientes. É preciso observar como essa regulamentação da Convenção transforma o cenário de assistência ao deficiente, na medida em que além dos impedimentos, avaliados no nível biomédico, o mau prognóstico também será decisivo para a concessão do benefício. Esses qualificadores não estão na Constituição Federal, tampouco na Convenção. Na Ação por Descumprimento de Preceito Fundamental (ADPF) n. 182, de 10 de julho de 2009, a Procuradoria Geral da República impugnou o conceito de deficiência disposto na redação original do $\S 2$ do artigo 20 da LOAS (BRASIL, 2009b). Mesmo incorporando a Convenção, a LOAS permanece instituindo restrições por vias transversas como a fixação da duração do impedimento pelo prazo mínimo de 2 (dois) anos.

\section{Conclusão}

A assistência social é um mecanismo de redução não apenas da pobreza, mas também da desigualdade. A Constituição de 1988 estabelece como objetivos principais da República erradicar a pobreza e 
reduzir as desigualdades sociais (artigo 3, III). Aigualdade é o parâmetro interpretativo dos direitos sociais e não qualquer outra ideia mais restritiva como a imposta pelo mínimo social. Todos os sujeitos de direitos que vivam situações de necessidade precisam acessar os mecanismos públicos de assistência. É por essa razão que o artigo 1 da LOAS é inconstitucional no que toca à referência aos mínimos sociais. Porque se filia a um paradigma que toma a sobrevivência como o parâmetro de aplicação dos direitos sociais, essa ideia se reflete no artigo 20 da Lei que regulamenta o BPC. Esses dispositivos desconsideram que a Constituição Federal é uma norma instituidora da igualdade.

Deficiência e velhice são os recortes de reconhecimento previstos pela Constituição Federal para a proteção social. A assistência social constitui um espaço visível de encontro entre reconhecimento e redistribuição. Assistir quem necessita é uma atividade do Estado e um dever público que convoca uma deliberação sobre quais necessidades precisam ser protegidas e em qual medida. Nesse sentido, a LOAS deve delinear essas duas questões, definindo os contornos de aplicação do princípio da igualdade na assistência social, com base na definição de deficiência que a Convenção integrou ao texto constitucional. Alguns importantes dispositivos da LOAS ameaçam a garantia de direitos fundamentais. Na concessão do BPC, a perícia médica deveria consistir na análise da correção da autodeclaração de que o requerente possui impedimentos que, em interação com as barreiras, restringem sua participação. $\mathrm{Na}$ forma instituída pela LOAS, são os peritos que decidem quais demandas refletem necessidades justas. Além disso, a LOAS deveria limitar-se ao previsto na Constituição Federal e dispor sobre os mecanismos de identificação da capacidade de automanutenção do indivíduo com deficiência ou idoso e sua família, o que é bem diferente do critério de extrema pobreza vigente. Por fim, fixar que os impedimentos de longa duração são aqueles que produzem efeitos pelo prazo mínimo de dois anos é desconsiderar os princípios da Convenção Internacional sobre os Direitos das Pessoas com Deficiência.

A proteção à pessoa com deficiência implica verdadeiramente reconhecer que as necessidades individuais são diferentes e que a determinação de mínimos não deve ser resultado de um cálculo orçamentário, mas da proteção às necessidades individuais. A proteção social reclama distribuições e reconhecimentos que sejam justos - portanto, que reconheçam diferentes necessidades. A deficiência provoca um dos fundamentos do justo - não há padrão típico da espécie, a pessoa típica, cuja distribuição por mínimos idênticos protegeria as necessidades. As pessoas com deficiência mostram que a diversidade humana e a diversidade de necessidades são nossa condição de existência compartilhada e que mínimos são insuficientes para proteger necessidades.

\section{Referências}

BRASIL. Constituição da República Federativa do Brasil. Brasília, 1988. Disponível em: 〈http://www.planalto.gov.br/ccivil 03/ constituicao/constitui\%C3\%A7ao.htm>. Acesso em: 14 ago. 2011.

Lei n. 8.742, de 7 de dezembro de 1993. Disponível em: <http://www010.dataprev.gov.br/sislex/paginas/42/1993/ 8742.htm>. Acesso em: 5 set. 2011.

Decreto n. 1.744, de 8 de dezembro de 1995. Disponível em: <http://www010.dataprev.gov.br/sislex/paginas/23/1995/ 1744.htm>. Acesso em: 3 set. 2011.

Decreto n. 6.214, de 26 de setembro de 2007. Disponível em: <http://www.planalto.gov.br/ccivil 03/Ato2007-2010/ 2007/Decreto/D6214.htm>. Acesso em: 14 ago. 2011.

Decreto n. 6.949, de 25 de agosto de 2009a. Disponível em: <http://www.planalto.gov.br/ccivil 03/ ato2007-2010/2009/ decreto/d6949.htm $>$. Acesso em: 14 ago. 2011.

Supremo Tribunal Federal. Ação por Descumprimento de Preceito Fundamental (ADPF) n. 182, de 10 de julho de 2009b. Disponível em: <http://www.stf.jus.br/portal/peticaoInicial/ verPeticaoInicial.asp?base $=A D P F \& s 1=182 \&$ processo $=182>$. Acesso em: 9 dez. 2011.

Portaria Conjunta n. 1, de 24 de maio de 2011 a. Disponível em: <http://www.mds.gov.br/sobreoministerio/ legislacao/assistenciasocial/portarias/2011/ Portaria\%20Conjunta\%20MDS-INSS\%20no\%201\%20de\%2024.05.11.pdf $>$. Acesso em: 14 ago. 2011.

Lei n. 12.435, de 6 de julho de 2011b. Altera a Lei n. 8.742, de 7 de dezembro de 1993. Disponível em: <https:// www.planalto.gov.br/ccivil 03/ ato2011-2014/2011/lei/

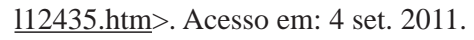

Lei n.12.470, de 31 de agosto de 2011c. Disponível em: <https://www.planalto.gov.br/ccivil 03/ Ato2011-2014/2011/ Lei/L12470.htm\#art3>. Acesso em: 9 dez. 2011.

DINIZ, D. O que é deficiência. São Paulo: Brasiliense, 2008.

DINIZ, D.; BARBOSA, L.; SANTOS, W. R. dos. Deficiência, direitos humanos e justiça. Sur, Revista Internacional de Direitos Humanos, v. 6, n. 11, p. 64-77, 2009.

FRASER, N.; HONNETH, A. Redistribution or Recognition?: a Political-Philosophical Exchange. Translators: Joel Golb, James Ingram, Christiane Wilke. London: Verso, 2003. 
PENALVA, J.; DINIZ, D.; MEDEIROS, M. Política assistencial, orçamento e justiça: o caso do Benefício de Prestação Continuada no Supremo Tribunal Federal. Sociedade e Estado, v. 25, n. 1, p. 53-70, jan./abr. 2010.

PEREIRA, P. A. P. Necessidades humanas: subsídios à crítica aos mínimos sociais. São Paulo: Cortez, 2006.

\section{Notas}

1 AConstituição Federal dispõe: “Art. 5: Todos são iguais perante a lei, sem distinção de qualquer natureza, garantindo-se aos brasileiros e aos estrangeiros residentes no país a inviolabilidade do direito à vida, à liberdade, à igualdade, à segurança e à propriedade, nos termos seguintes: [...] §3. Os tratados e convenções internacionais sobre direitos humanos que forem aprovados, em cada Casa do Congresso Nacional, em dois turnos, por três quintos dos votos dos respectivos membros, serão equivalentes às emendas constitucionais" (BRASIL, 1988).

2 A referência é ao debate entre Fraser e Honneth (2003).

3 "Pessoas com deficiência" e "deficientes" são utilizados como sinônimos neste artigo. Para uma revisão dos impactos políticos desses conceitos, ver Diniz (2008)e Diniz, Barbosae Santos (2009).

4 Para uma análise mais detalhada sobre o tema, conferir Penalva, Diniz e Medeiros (2010).

5 Algo semelhante ocorre no sistema penal quantoà períciapsiquiátrica para identificação da insanidade mental e para a comprovação da cessação de periculosidade dos portadores de sofrimento mental em conflito com a lei, para os quais são aplicadas medidas de segurança.

\section{Janaína Lima Penalva da Silva}

j.penalva@anis.org.br

Doutora em Direito pela Universidade de Brasília (UnB)

Professora Adjunta da Faculdade de Direito da UnB Pesquisadora da Anis: Instituto de Bioética, Direitos Humanos e Gênero

\section{Debora Diniz}

anis@anis.org.br

Doutora em Antropologia pela UnB

Professora do Programa de Pós-Graduação em Política Social da UnB

Pesquisadora da Anis: Instituto de Bioética, Direitos Humanos e Gênero
Anis: Instituto de Bioética, Direitos Humanos e Gênero

<http://www.anis.org.br/>

Caixa Postal 8011

Brasília - Distrito Federal

CEP: 70670-973 